\title{
Millennium Development Goal Seven, Target 7C; Achievements and Barriers in Kenya's Arid and Semi-arid Land
}

\author{
Abdi D. Osman ${ }^{1}$, Priscilla Robinson ${ }^{1}$, Mutuku Mwanthi ${ }^{2}$, Vivian Lin $^{1} \&$ Darryl Jackson ${ }^{3}$ \\ ${ }^{1}$ La Trobe University, Faculty of Health Sciences, School of Public Health Bundoora Campus \\ ${ }^{2}$ University of Nairobi, Faculty of Health Sciences, School of Public Health, Nairobi, Kenya \\ ${ }^{3}$ Private Water and Sanitation Consultant \\ Correspondence: Abdi D. Osman, La Trobe University, Faculty of Health Sciences, School of Public Health \\ Bundoora Campus, Victoria, 3086, Australia. Tel: 966-536-195-061. E-mail: abdosma@gmail.com
}

Received: September 29, 2013 Accepted: October 20, 2013 Online Published: October 22, 2013

doi:10.5430/wjss.v1n1p48 URL: http://dx.doi.org/10.5430/wjss.v1n1p48

\begin{abstract}
Introduction: Wajir County is part of Kenya's arid land in North Eastern Kenya and has a population of approximately 662,000 (2009 census). The County's main water supply is from underground shallow wells, and for long, sanitation options have been restricted to open defection and bucket latrines due to susceptibility of the shallow aquifer to contamination. This is assessed against Millennium Development Goals (MDG) target achievements.

Objectives: To describe the trends of diarrhoeal and other waterborne diseases and to ultimately measure MDG targets performance.

Methods: Combined study designs were employed to investigate the existence of an association between water quality and water borne diseases in children. Data were entered into a database and analysed in Stata 10 software.

Results: Data were obtained using; survey questionnaires from 44 households, water samples from 46 shallow wells and stool samples from 4 children. The study indicated $27 \%$ prevalence of diarrhoeal diseases in children, presence of micro-organisms and high levels of properties and chemicals in the water, notably lead.

Discussion and conclusion: Although all the water samples were grossly contaminated, the study does not provide evidence for the water-borne diseases in children being linked to local groundwater quality due to poor performance of our stool sample collection. There are concerns about the high concentrations of lead in the water with uncertainties of its cause. MDG targets are unlikely in 2015.
\end{abstract}

Keywords: contamination, diarrhoeal diseases, groundwater, MDG, Wajir

\section{Introduction}

\subsection{Background}

Wajir County has a population of 661,941 according to the 2009 national census (Kenya National Bureau of Statistics, 2010) and is inhabited mainly by the Somali ethnic group. The county shares a national border with Somalia, and has the highest human poverty index and poor infrastructure development of all of Kenya (Kumssa et al., 2009; Dobie, 2001; Ibrahim and Jenner, 1996). The County has similar demographics and socio-economic status as the rest of Kenya's arid and semi-arid areas. A research study was undertaken in Wajir County, North Eastern Kenya from April to June 2010 to examine water quality and prevalence of water-borne diseases in children and equally made inferences to achievements towards MDG 2015 water and sanitation targets.

Wajir town is the urban centre of the County. Geologically, the town is underlain by limestone (Joubert, 1963). The shallow groundwater is the town's main water supply; mainly accessed using manually constructed shallow wells (Fisher, 2004; Mailu, 1997). As there has been no sewerage infrastructure the sanitation options for the town have historically been either open defection or bucket sanitation (Fisher, 2004; Integrated Regional Information Network, 2009).

The population is in general, a traditional pastoralist community. However following recurrent droughts during the last two decades, which severely decimated the livestock (Government of Kenya, 2009), there has been an immense 
population displacement from the rural areas to the main town of Wajir (Chinyama, 2011), leading to rapid population growth and settlement expansion in the town. In turn this has made the traditional water and sanitation systems unsustainable, and the community has had no option but to increase the number of wells and adopt various methods of sanitation, based on individual household's economic status. In the last two decades, septic tanks and Ecological Sanitation were more widely adopted. According to a 2008 report from the Wajir Department of Public Health and Sanitation, the town had latrine coverage of 28\% (with approximately4,600 bucket latrines and 200 septic tanks) to service a population of over 600,000 people (District Public Health Report, 2008).

\subsection{The Issue}

According to local surveillance reports, water borne diseases outbreaks in the County are reported to be common, with cholera epidemics during rainy seasons (IFRC, 2008, WHO, 2001a, ALRMP, 2009, ALRMP, 2008, 2008).

Wajir town comprised the town centre and four satellite villages which were selected as the study sites in order to explore the study objective. The selected area's water table was known to be very high and the sanitation options and practices were limited. The shallow aquifer was estimated to cover an area of $9 \mathrm{~km}^{2}$. Previous reports have associated the prevalence of diarrhoeal diseases with the shallow Wajir town aquifer. To maximise the probability of identifying links between contaminated water supplies and childhood diarrhoeal disease, the study planned field investigations during the rainy season months of April to June 2010. However, the amount of rainfall has been variable and below the expected level for most of the last two decades. Unfortunately, during this study the expected heavy rains did not eventuate.

The Millennium Development Goal (MDG) call for sustainable access to safe water and basic sanitation in the world is targeted to be halved by the year 2015 (WHO, 2012). The proportion of the population in Kenya with access to safe drinking water sources and sanitation was reported to be $59 \%$ and $31 \%$ respectively (WHO, 2011b) with latest reports ranking Kenya among the top ten countries without improved drinking water source (UNICEF and WHO, 2012). A United Nations Environmental Programme (UNEP) report indicated that, Kenya was unlikely to attain the MDG targets. Kenya's population with access to improved water source and sanitation was $41 \%$ and $39 \%$ during the 1990 s and was targeted to be $82 \%$ and $78 \%$ respectively in the 2000 s, but the country managed to achieve only $57 \%$ and $42 \%$ in 2008 (UNEP, 2009). Sanitation targets of the country improved by only 3\% over a decade and North Eastern province where Wajir County is located was the worst performing area, with only $36.7 \%$ of its population said to have access to improved sanitation (UNEP, 2009). On realising the inability to achieve the MDG targets, the government of Kenya shifted its goals further to the vision 2030 programme (GoK).

\section{Methods}

\subsection{Objective}

The objective of the study was to describe the trends of diarrhoeal and other waterborne diseases and to assess and relate factors that may enhance the occurrence of diarrhoeal disease and water borne diseases and ultimately measure MDG targets performance.

\subsection{Sample Size and Selection}

The sample size was calculated using EpiStatCalc. The data entered into the statistical calculator were based on the following information gathered from the existing literature on the target population; target number of households was 31,428 with disease prevalence of $60 \%$ and worst acceptable prevalence of $75 \%$ (Integrated Regional Information Network, 2009; Mwabu, et al, 2003 and Stevens 2000). Following the entry of this data, EpiStatCalc produced an output sample result of 41 households with significance level for this study set at 0.05 (i.e. $95 \%$ confidence level) and power of $80 \%$. Taking into consideration all other possible factors like non-homogeneity and the fact that quadrate sampling method was used to complement the random allocation (Brown et al, 2001; Noji, 2005); the sample size was set slightly above the calculated sample for recruitment at 50 households. This sample was found to be representative enough for the target population and was geographically and randomly distributed equally among Wajir Town settlements coded as H, T, AM, W and J. As anticipated and considered in the sampling method, some localities were found to be smaller than the expected size and hence a decrease in the total random samples to 44 households and 46 drinking water wells. Figure 1 below indicates the locational map of Wajir in Kenya. 


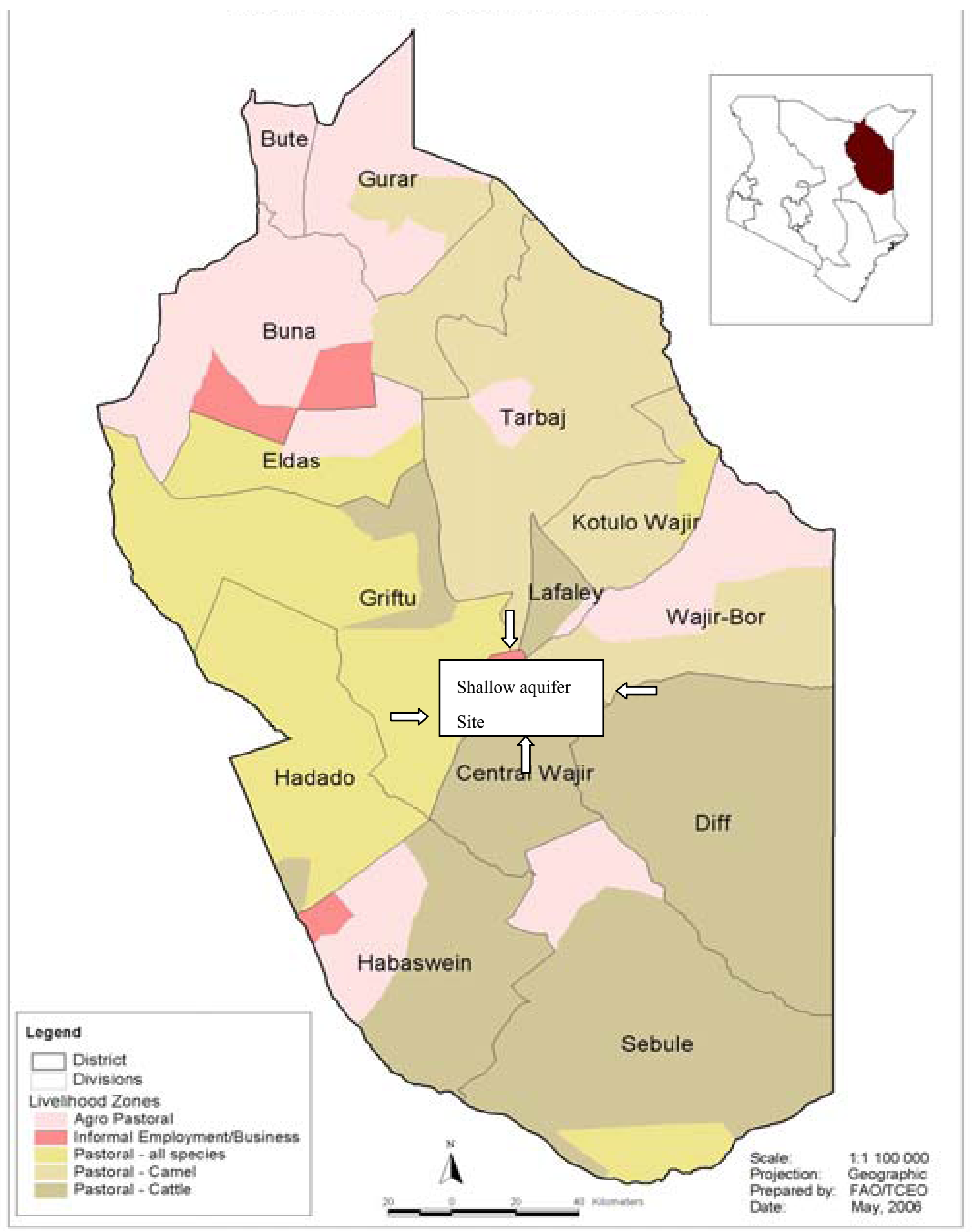

Figure 1. Map of Wajir County (inset, map of Kenya showing location of Wajir)

Adapted from (ALRMP, 2009) with permission 


\subsubsection{Data Collection Tools}

The items for data collection were;

- Survey questionnaires tools for households.

- Metric measuring tapes for measuring sanitation and water source distances and water source surface depth.

- $\quad$ Equipment's for obtaining water sample drawn from shallow wells of households as shown in figures 2A, 2B and 3 below.

- $\quad$ Stool samples containers.

\subsection{Study Participants}

A competent adult member of the selected household was requested to respond to our questionnaire after obtaining an informed consent from them. A total of 44 randomly selected households consented to participate and were successfully recruited for the questionnaire survey. Water samples were obtained from a total of 46 wells of which 44 wells were the primary water source of the selected households and two wells were communal wells used by a cluster of households.

Stool sample were to be obtained from all the selected households with a child less than 5 years old following consent by their parents. The parents were given a container labelled with a code number and advised to take the sample to a nearby laboratory where arrangements were made $a$ priori. The stool sample strategy largely failed: $66 \%$ of the total households reported having a child less than five years old, however only $41 \%$ among these households consented to give a stool sample of which only $14 \%$ took the sample to the designated laboratories.

\subsection{Study Details}

A cross-sectional design was chosen as the study design of choice since we were investigating a point and five years period disease prevalence and aetiology of waterborne diseases in children.

The study adhered to the required ethical regulation as per the approval of La Trobe Universities Human ethics committee and field data collection permission was granted by Kenya's National Council for Science and Technology. All participants consented to participate at own will and were advised about withdrawal options if they wished to withdraw.

Using structured survey questionnaire, data were gathered from households on waterborne diseases occurrence, hygiene practice and health seeking behaviours. Household's shallow wells depth and the distance from the nearest sanitation were also measured.

The water samples were sent to microbiological and chemistry laboratories for analysis of pre-selected micro-organisms and water properties and chemicals. The water samples were obtained using either a $250 \mathrm{mls}$ sterile bottle for microscopic testing; or by $0.45 \mu \mathrm{m}$ filter for microbiological culture where ten litres of water were filtered using a pressure pump and the filter which was handled in a sterile technique was stored in double strength peptone-water for transportation. Also, water samples were obtained from the same wells in one litre plastic bottle for chemical analysis. All the water samples were transported by air from Wajir town to Nairobi and delivered to the testing laboratories within 24 hours of collection. A total of six microbiological parameters and eleven water properties and chemical parameters, which were selected on the basis of being World Health Organization's priority diseases causing elements (WHO, 2001b) were tested for. The water sample collection process is shown in figures $2 \mathrm{~A}, 2 \mathrm{~B}$ and 3 below. The stool samples were also cultured at local laboratories to isolate micro-organisms.

All the data were entered into a database built in EpiData, exported to and analyzed in Stata 10 software to test the existence of a relationship between the questionnaire variables responses, the findings in the water and stool samples. Differences in the distribution of categorical variables were tested using $\chi^{2}$ tests and t-tests to compare continuous data, and variable relationships were tested using correlation tests. 


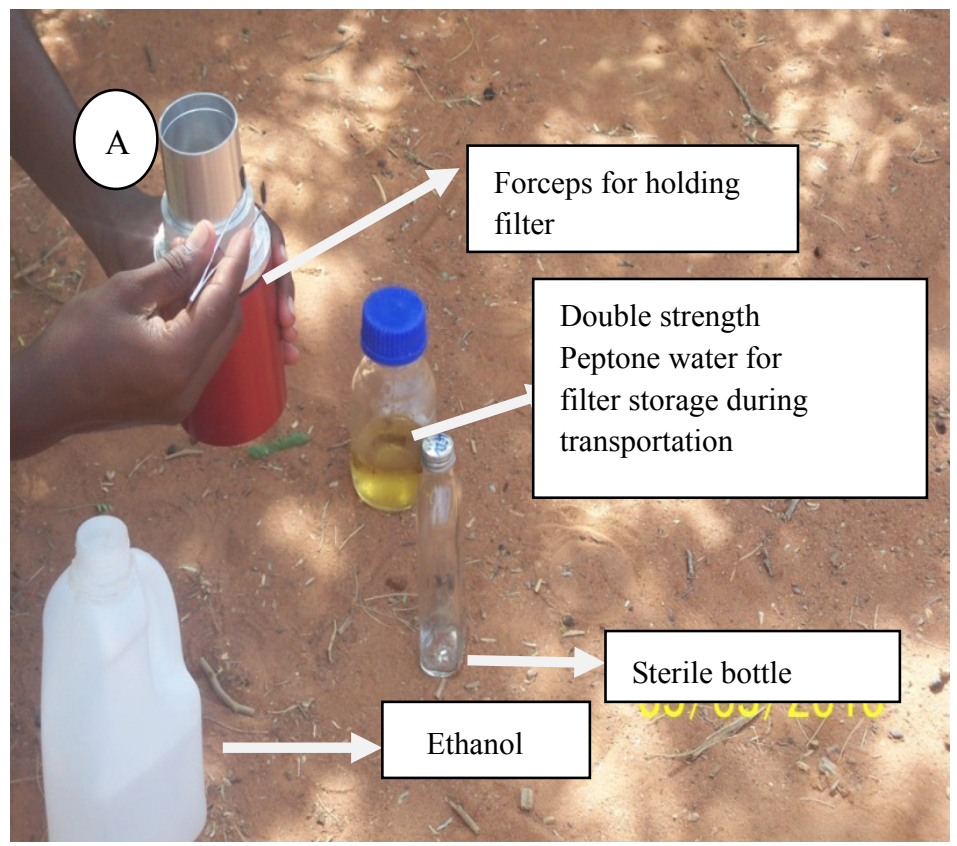

Figure 2. A) Water sample collection tools

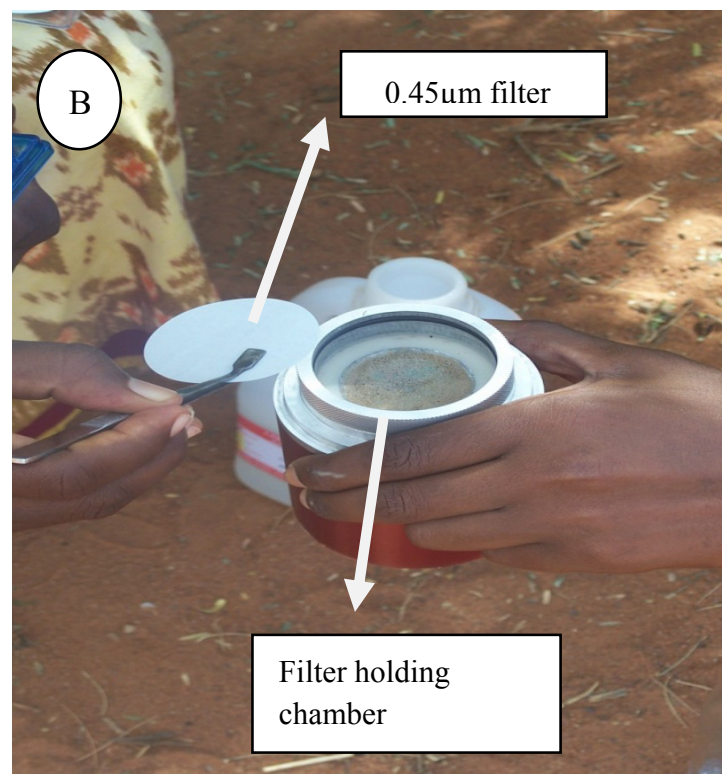

Figure 2. B) Water sample collection tools

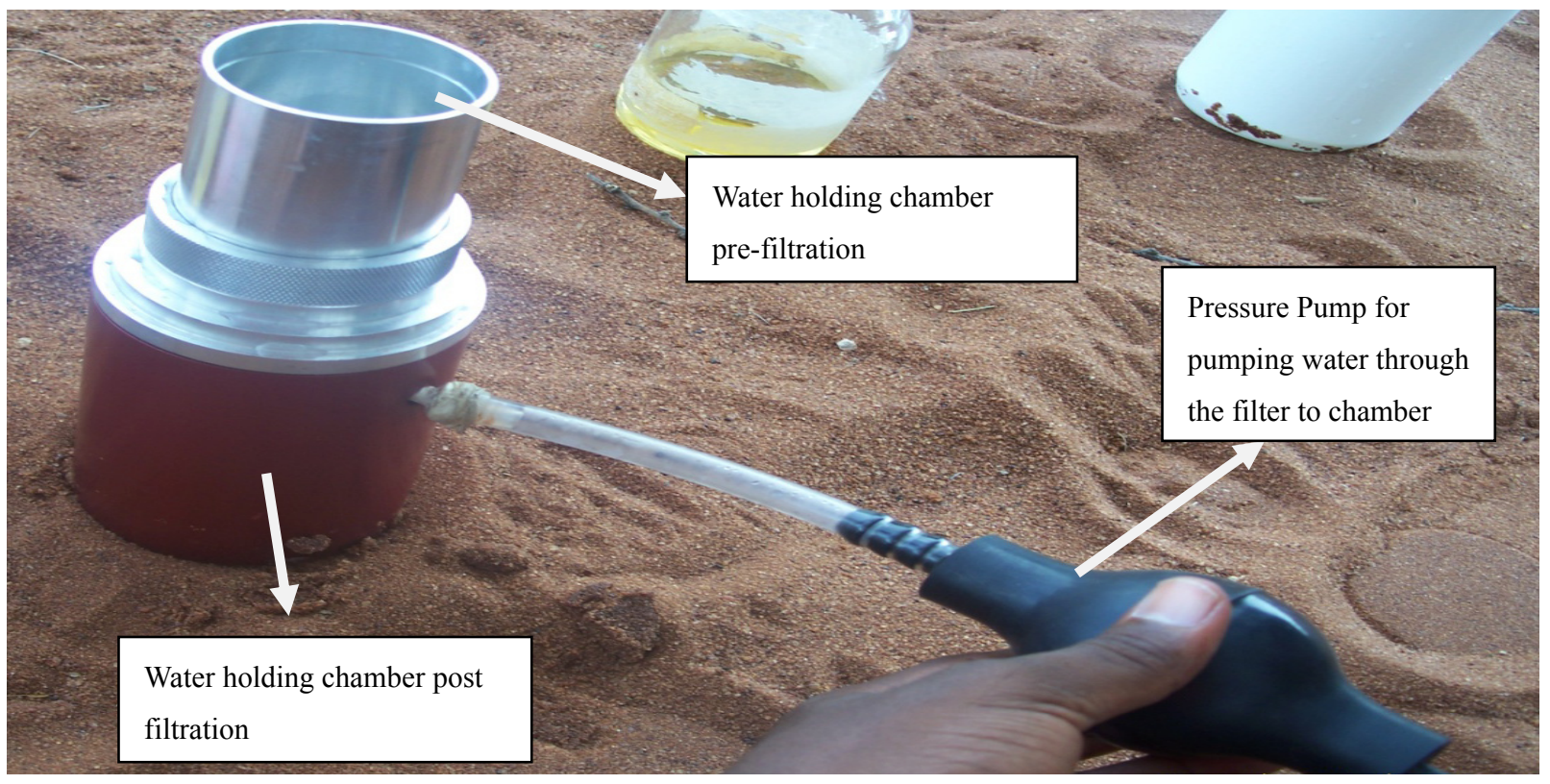

Figure 3. Water sample collection tools

\section{Results}

\subsection{Questionnaire Variables Results}

The following health and hygiene etiological variables were analysed from the survey questionnaire feedback. Drinking water samples were obtained from the following sources: unprotected wells $76 \%$, protected wells $15 \%$; and from others sources including (tubed well, piped to yard, cart delivery and rain water collection) $9 \%$. The bucket 
sanitation system was reported to be the most used (49\%) compared with 14\% each for open defection, septic tank and composite (Ecological Sanitation) and 9\% using other methods including combined methods (pit latrines, either septic or bucket and either composite or bucket).

All adult respondents $(\mathrm{n}=43)$ apparently wash their hands with either water only (51\%), water with soap (39\%), water with either sand or soap ( $9 \%$ ) or water with sand and water with detergent ( $2 \%$ each). Of the families who responded to the question on children's hand washing behaviour $(n=37), 16 \%$ reported that the children do not wash their hands after toileting, $51 \%$ wash with water only, $24 \%$ water and soap, $5 \%$ water with either soap or sand and $3 \%$ water with detergent.

In order to assess the role of knowledge gap on disease prevalence, relationship between health safety practice information and education level was found to be statistically insignificant ( $\mathrm{p} 0.12$ ) whereas; similarly water and sanitation safety practice information and education level was not significant (p 0.32).

Knowledge on construction requirement guidelines for water sources and sanitation was lacking generally with only $4.7 \%$ of the 43 household who responded believing that they had the appropriate knowledge. In order to investigate drinking water contamination by excreta seepage, distances between the main sanitation used by the household and water source were measured $(n=46)$; distances of greater than 30 meters were set to be ideal (as reported to be recommended by the local authority and public health) and this was observed in $30.4 \%$ of the wells, followed by 10-15 meters in 26\% while the shortest distance of 5-10 meters was measured in $13 \%$ and for the purpose of waste transportation from the source to the water table considering natural filtration which can be enhanced by the depth, the wells water surface depth were measured $(\mathrm{n}=42)$ and this ranged from 7 meters to 15 meters.

\subsection{Water and Stool Analysis Results}

Table 1 below shows the values of water properties and chemical contaminants which can be detrimental to health if found in the water at concentration levels higher than World Health Organizations recommended levels (APPS Laboratories, WHO, 2011a). The distribution of these items was found to be adopting a geographical pattern which may suggest geological differences between the localities even though they are all within $9 \mathrm{KM}^{2}$ area.

Table 1. Summary of test results for well water chemical levels $(n=46)$

\begin{tabular}{lllll}
\hline Variable & Mean & $\begin{array}{l}\text { Range of } \\
\text { parameters }\end{array}$ & $\begin{array}{l}\text { WHO } \\
\text { Guideline } \\
\text { values }\end{array}$ & $\begin{array}{l}\text { 1- sample T-Test } p \text { - } \\
\text { Value vs. guideline } \\
\text { value }\end{array}$ \\
\hline $\mathrm{pH}$ & 7.75 & $7.4-8.2$ & $6.5-8.5$ & 0.01 \\
Electrical Conductivity & 2190.74 & $1124-3900$ & $100^{+}$ & 0.01 \\
Total Dissolved Solids & 1534.11 & $780-2725$ & 1000 & 0.01 \\
Hardness & 836.74 & $450-3200$ & 500 & 0.01 \\
Nitrite & 0.05 & $0-0.52$ & 3 or $0.2^{ \pm}$ & 0.01 \\
Iron & 0.07 & $0-0.47$ & $0.3-3$ & 0.01 \\
Manganese & 0.04 & $0-0.29$ & 0.4 & 0.01 \\
Lead & 0.03 & $0-0.30$ & 0.01 & 0.08 \\
Fluoride & 0.49 & $0.0 .2-0.8$ & $0.5-1.5$ & 0.54 \\
Sodium & 208.87 & $20.58-761.46$ & 200 & 0.71 \\
Potassium & 27.03 & $5.93-75.7$ & - & - \\
\hline
\end{tabular}

+ Electrical conductivity is expected to be measuring less than 100 micro Siemens per $\mathrm{cm}(\mu / \mathrm{cm})$ in most fresh drinking water, though some places set standards close to $1000 \mu / \mathrm{cm}$ (APPS Laboratories).

\pm Nitrite levels $3 \mathrm{mg} / \mathrm{l}$ for short term exposure and $0.2 \mathrm{mg} / 1$ for long term exposure.

The five locations in Wajir town were coded as H, T, AM, W and J. Generally, water properties, chemicals and microbes levels/counts took a pattern such that, levels are within a close range in certain geographical areas and varies with other areas. Wells in location ' $H$ ' were found to have very high lead levels whereas location ' $T$ ' had highest sodium levels. Location ' $\mathrm{W}$ ' where there was questionable dumping of waste which the government of Kenya acknowledged to have buried pesticide filled drums (Note 1) was conspicuously found to have the lowest levels of all measured parameters. Details of these findings are listed in table 2 below. 
Table 2. Proportion of contaminated wells by area

\begin{tabular}{|c|c|c|c|c|}
\hline Area & Total wells & $\begin{array}{l}\text { Lead }(\% \\
\text { contaminated, } \\
\text { range) }\end{array}$ & $\begin{array}{l}\mathrm{Na}(\% \text { contaminated, } \\
\text { range })\end{array}$ & $\begin{array}{l}\text { Coliform count }(\% \\
\text { contaminated, range } \\
\text { and } \%>1800 \text { counts) }\end{array}$ \\
\hline $\mathrm{H}$ & & $18 \%,(0.07-0.30)$ & $4 \%,(216.22-254.88)$ & $22 \%,(425->1800,90 \%)$ \\
\hline $\mathrm{T}$ & & $2 \%,(0.09)$ & $22 \%,(288.64-716.46)$ & $22 \%,(8->1800,20 \%)$ \\
\hline $\mathrm{AM}$ & & 0 & $4 \%,(217.06-251.70)$ & $17 \%,(200->1800,38 \%)$ \\
\hline $\mathrm{W}$ & & 0 & 0 & $17 \%,(3-1600,0 \%)$ \\
\hline \multirow[t]{2}{*}{$\mathrm{J}$} & & 0 & $9 \%,(204.62-438.98)$ & $22 \%,(225->1800,40 \%)$ \\
\hline & $\begin{array}{l}\text { Total wells } \\
\text { contaminated } \\
\text { beyond guideline } \\
\text { values }(n=46)\end{array}$ & $9(20 \%)$ & $18(39 \%)$ & $46(100 \%)$ \\
\hline
\end{tabular}

Lead WHO guideline values $=0.01 \mathrm{mg} / 1$

Sodium $(\mathrm{Na})$ guideline values $=200 \mathrm{mg} / 1$

Coliform count guideline values $=$ none in $100 \mathrm{mls}$

Microbiological testing of the sampled well waters returned results of high coliform counts $(n=46)$ in the range of counts of 3/100mls to greater than 1800/100mls with a mean of 1048 and SD. 762 . WHO recommends the use of coliform count testing only as a substitute to $E$. Coli, especially in tropical areas where many bacteria of no sanitary significance occur, but recommends that coliform and E. Coli bacteria should normally be undetectable in $100 \mathrm{ml}$ drinking water sample (WHO, 2011a). Table 2 above indicates the distribution of coliforms (when counts are $>1800 / 100 \mathrm{ml}$ of water) among the settlements. Wells located at area ' $\mathrm{H}$ ' had the highest count where as those located at ' $\mathrm{W}$ ' had the least counts. The table also indicates Lead which was the most important toxic chemical isolated and the geographical pattern that exists between lead and coliform contaminations.

E. Coli was found to be present in 38 wells of the sampled 46 wells in a range of one to $>1800$ counts per $100 \mathrm{mls}$, mean 87.5 and SD 292. Of the 38 wells which E. Coli were detected, 37 had ranges between one to 275 counts per $100 \mathrm{ml}$ with one well having $>1800$ counts per $100 \mathrm{ml}$. When this well is controlled as an outlier, mean $E$. Coli for the 37 wells is 41 with SD of 65 .

Correlation test indicated that $E$. Coli had a positive relationship with nitrite at 0.72 , positive relationship with depth of wells ( 0.08 for all wells and 0.41 when outlier well controlled) and weak negative relationship with wells treatment -0.08 which shows the effectiveness of the chlorine treatment against $E$. Coli. This was despite the fact that the numbers of reported treated wells were very minimal at $8.7 \%$.

All laboratory culture results of the sampled wells $(\mathrm{n}=46)$ yielded positive bacterial results. Proteus species were isolated from $89.13 \%$ of the wells and all the rest had $E$. Coli isolated. The four stool samples obtained from children under the age of 5 years, all symptomless, were also cultured for the presence of pathogens. E. Coli was isolated from all the samples.

\subsection{Summary Findings}

The reported prevalence of diarrhoeal diseases in our survey questionnaire is $27 \%$ and all were reported to have occurred during the first quarter of 2010 (the questionnaire variable covered incidence during past five years). All those affected were children under 5 years of age. There were no cases of cholera reported by the respondents during the last five years. The laboratory result also indicated that, all the water wells tested positive for coliform, all except eight wells had $E$. Coli presence, and 41 wells had proteus species isolated through incubation and culture while the remaining 5 had $E$. Coli isolated.

\section{Discussion}

In examining groundwater contaminants, several factors may enhance, hinder or delay contamination. Of essence is contaminant transport process which plays a major role through advection, diffusion and dispersion (Lawrence et al, 2001). Similar study findings reported the susceptibility of shallow aquifer with sandy soil to contamination (Banks et al., 2001) and in this study where $80 \%$ of the wells were less than 10 meters deep with loose sandy soil and limestone rocks, the contaminant load was expected to be high and hence, all the wells were found to have a positive coliform count and $67 \%$ of the wells had the presence of nitrite of which both are indicators of faecal contamination 
(WHO, 2011a). However, the study found a positive relationship between the depth of the wells and the contaminants at 0.08 , which means the deeper the well, the greater the likelihood of finding these organisms and this may be as a result of the diagenetic (physical and chemical changes) of the carbonate rocks, alterations in the pore structure of the rocks and water velocity all of which affects permeability (Baechle et al., 2006).

Another contaminant source examined is the proximity of wells to the sanitation systems. The toilets were found to be closer to the water sources since almost $70 \%$ of the toilets were at distance less than the locally recommended 30 meters to the water source and $13 \%$ being at a distance less than 10 meters. This combined with the nature of the geology (highly permeable rock structure susceptible to fractures) increased the chances of contamination and hence resulted the water samples from all the 46 wells to test positive for both proteus species and E.Coli following incubation and culture. The presence of this organisms which both belonged to the intestinal flora of Enterobacteriaceae family confirm the faecal contamination of the water (Suthar et al., 2009, Shittu et al., 2008).

Previous studies have reported a high prevalence of water borne diseases in Wajir (IFRC, 2008, WHO, 2008, WHO, 2001a, WHO, 2006) and this study reports a prevalence of $27 \%$ for diarrhoeal diseases with positive findings of micro-organisms in the drinking water sources. The properties and chemical content of the water were found to be out of the WHO recommended range (WHO, 2011a) but no diseases could be attributed to this as the community is known to be reluctant in seeking medical assistance at the hospital due to perception of poor services (Jaldesa et al, 2005) and hence poor record keeping.

There were four important limitations in this study;

1. The expected rainfall during data collection did not eventuate.

2. The use of self-reported questionnaires in the study may have been a weakness as the risks of validity in the responses could not be controlled.

3. The low number of children's stool samples, which were well below the expected sample, made it hard to critically examine possible association between the water quality and water-borne diseases in children.

4. The lack of onsite laboratories at the study site to minimise the time lost in sample transportation and possibly more accurate detection of the water contaminants.

\section{Conclusion}

In this study, the survey questionnaire revealed a diarrhoeal diseases prevalence of $27 \%$ during the first quarter of the year 2010 in Wajir town population and all cases were reported to be children less than five years old. The laboratory water test revealed the presence of microbes with the culture isolation of E.Coli and proteus species in all the wells and high microbiological counts of E.Coli and coliform in the majority of the wells indicating faecal contamination of the water. Chemically, the water contained properties and chemical levels beyond the international recommendations both for aesthetics and health. Particularly, the very high lead level in the water was worrying and this needs to be addressed. Interestingly, the distribution pattern of the contaminants and chemical contents of Wajir town wells related more to a geographical pattern than to sanitation proximity and even the very high lead levels were found mostly (89\%) in one locality. This calls for a review of current groundwater contamination programmes and consideration of the geology as an important factor in contamination cascade in Wajir as well as all the arid and semi-arid regions of Kenya.

From this study, it can be concluded that MDG 7, target 7C for the year 2015 in Wajir County is not achievable based on the research findings. With the challenges of rampant population growth and the evolving sanitations both in mode and quantity which are further endangering the water and sanitation services in Wajir County and the lack of roadmap from the government to counter the effect, it is questionable whether this goals will be achieved even with Vision 2030. A better and practical roadmap tailored to specific needs of specific localities like Wajir considering its geo-locality and socio-economic status rather than mere setting of standard global goals which for long were unattainable may alleviate this and similar issues and hence, even 2030 may not be an option.

Based on the results of the study, it is concluded that:

- Aquifer fractures and links do exist in Wajir aquifer based on the microbial results irrespective of the mode of sanitation, depth of the wells and distance of sanitation to water source.

- There was an increased risk of microbial contamination to the groundwater of Wajir town from onsite sanitation and this could be associated to the occurrence of waterborne diseases in children which was reported in this study to be prevalent at $27 \%$. 
Therefore, further investigations are recommended to address the following issues/questions:

1. The study found high lead levels with no obvious source. Further investigation is needed to understand the occurrence of the lead.

2. The $9 \mathrm{~km}^{2}$ Wajir town aquifer; is it of the same geology as stated by Joubert (1963), are there significant differences in the diagenetics of the rocks, alterations in the rock's pore structure and velocity altering the chemical components?.

3. What are the effects of the chemicals dumped (as reported in the inter-ministerial report commissioned by the Kenyan parliament) in Wajir town on water quality? And did this contamination played any role in influencing the contents of wells in location "W"?

\section{References}

ALRMP. (2008). Drought Monthly Bulletin For March. Retrieved from http://www.aridland.go.ke/bullentins/2008/mar/wajir.pdf

ALRMP. (2009). Drought Monthly Bulletin, April 2009. Nairobi. Retrieved from http://www.aridland.go.ke/bullentins/2009/april/wajir.pdf

APPS Laboratories Salinity - what do those figures mean? Retrieved from http://www.appslabs.com.au/salinity.htm

Baechle, G. T., Weger, R., Eberli, G. P., \& Colpaert, A. (2006). Pore size and pore type effects on velocity Implication for carbonate rock physic models. Sound of geology. Bergen, Norway. Retrieved from http://mgg.rsmas.miami.edu/students/greg/cipr_baechle-final.pdf

Banks, W. S. L., Klohe, C. A., \& Battigelli, D. A. (2001). Occurrence and Distribution of Enteric Viruses in Shallow Ground Water and Factors Affecting Well Vulnerability to Microbiological Contamination in Worcester and Wicomico Counties, Maryland Baltimore, U.S. geological survey. Retrieved from http://pubs.usgs.gov/wri/wri01-4147/wrir-01-4147.pdf

Brown, V., Jacquier, G., Coulombier, D., Balandine, S., Belanger, F., \& Legros, D. (2001). Rapid Assessment of Population Size by Area Sampling in Disaster Situations. Disaster, 25(2), 164-171. http://dx.doi.org/10.1111/1467-7717.00168

Chinyama, V. (2011). Kenya: Families struggle to cope with loss amidst drought. IN UNICEF (Ed.). Retrieved from http://www.unicef.org/infobycountry/kenya_59618.html

District Public Health Report. (2008). Brief background of water and environmental sanitation in Wajir east district (obtained with permission). Wajir, Ministry of Public health and Sanitation.

Dobie, P. (2001). The Global Drylands Partnership. POVERTY AND THE DRYLANDS Nairobi, UNDP. Retrieved from http://arabstates.undp.org/contents/file/Poverty-and-the-Drylands-Challenge-Paper.pdf

Fisher, J. (2004). The unsung heroes of Wajir IN BBC (Ed.). BBC. Retrieved from http://news.bbc.co.uk/1/hi/world/africa/3764556.stm

GOK Vision 2030. Nairobi. Retrieved from http://www.vision2030.go.ke/index.php

Government of Kenya. (2009). Draft National Policy for Disaster Management. Ministry of State for Special Programmes. Retrieved from www.kecosce.org/.../DRAFT_DISASTER_MANAGEMENT_POLICY.pdf

Ibrahim, D., \& Jenner, J. (1996). Wajir Community Based Conflict Management. USAID Conference on Conflict Resolution in the Greater Horn of Africa. USAID. Retrieved from http://www.payson.tulane.edu/conflict/Cs\%20St/JANFIN2.html

IFRC. (2008). KENYA: FLOODS. Appeal Extension-Recovery Phase. Geneva, International Federation of Red Cross and Red Crescent Societies, 2008. Retrieved from http://www.ifrc.org/cgi/pdf_appeals.pl?06/MDRKE00305.pdf

Integrated Regional Information Network. (2009). KENYA: Replacing the bucket latrine. Retrieved from http://www.irinnews.org/Report.aspx?ReportId=86896

Jaldesa, G. W., Askew, I., Njue, C., \& Wanjiru, M. Female Genital Cutting among theSomali of Kenya and Management of its Complications, 2005. Retrieved from http://www.popcouncil.org/pdfs/frontiers/FR_FinalReports/Kenya_Somali.pdf

Joubert, P. (1963). Geology of the Wajir-Wajir Bor area; degree sheet 31, N.E. and N.W. quarters, Kenya Ministry of 
Environment and Natural Resources, Mines and Geology Department, Nairobi, Kenya.

Kenya National Bureu of Statistics. (2010). Kenya 2009 Population and housing census highlights. Nairobi, Kenya National Bureau of Statistics. http://www.knbs.or.ke/Census\%20Results/KNBS\%20Brochure.pdf

Kumssa, A., Jones, J. F., \& Williams, J. H. (2009). Conflict and Human Security in the North Rift and North Eastern Kenya. International Journal of Social Economics, 36. http://dx.doi.org/10.1108/03068290910984786

Lawrence, A. R., Macdonald, D. M. J., Howard, A. G., Barrett, M. H., Pedley, S., Ahmed, K. M., \& Nalubega, M. Guidelines for Assessing the Risk to Groundwater fromOn-Site Sanitation (No. CR/01/142). London: British Geological Survey. Natural Environment Research Council, 2001.

Mailu, G. M. (1997). The impact of urbanization on groundwater quality in Wajir Town, Kenya. IAHS-AISH Publication.

Mwabu, G., Kimenyi, M., Kimalu, P., Nafula, N., \& Manda, D. (2003). Predicting Household Poverty: A Methodological Note with a Kenyan Example. African Development Review, 15(1). http://dx.doi.org/10.1111/1467-8268.00064

Noji, E. K. (2005). Estimating population size in emergencies. Bulleting of World Health Organization, 83(3).

Shittu, O. B., Olaitan, J. O., \& Amusa, T. S. (2008). Physico-Chemical and Bacteriological Analyses of Water Used for Drinking and Swimming Purposes in Abeokuta, Nigeria. African Journal of Biomedical Research, 11, 285-290. http://dx.doi.org/10.4314/ajbr.v11i3.50739

Stevens, D. (2000). Nutrition Survey in Central Division, Wajir District North Eastern Province, Kenya. Retrieved from http://pfeda.univ-lille1.fr/Ethiop/Docs01/0105scf.pdf

Suthar, S., Chhimpa, V., \& Singh, S. (2009). Bacterial contamination in drinking water: a case study in rural areas of northern Rajasthan, India. Environmental Monitoring and Assessment, 159, 43-50. http://dx.doi.org/10.1007/s10661-008-0611-0

UNEP. (2009). KENYA; Atlas of our changing environment. Retrieved from http://www.unep.org/dewa/africa/kenyaatlas/PDF/KenyaAtlas_Chapter2.pdf

UNICEF \& WHO. (2012). Progress on Drinking Water and Sanitation update. Retrieved from http://whqlibdoc.who.int/publications/2012/9789280646320_eng_full_text.pdf

WHO. (2001a). Cholera Cases and Deaths in Kenya (firtsr half, 2001). Geneva, EPI/IDS Bulletin. Retrieved from http://www.afro.who.int/csr/ids/bulletins/eastern/jul2001.pdf

WHO. (2001b). Waterborne Disease Surveillance: Goals and Strategies. Budapest, Regional office for Europe. Retrieved from www.cdc.gov.tw/downloadfile.aspx?fid=99A0E90B02223CDE

WHO. (2006). Wajir District Profile (SITREP). Retrieved from http://www.who.int/hac/crises/ken/sitreps/Kenya_Wajir_district

WHO. (2008). Cholera Country Profile: Kenya. Geneva, World Health Organization. Retrieved from http://www.who.int/cholera/countries/KenyaCountryProfileMay2008.pdf

WHO. (2011a). Guidelines for Drinking-Water Quality, Fourth Edition. Retrieved from http://whqlibdoc.who.int/publications/2011/9789241548151_eng.pdf

WHO. (2011b). World Health Statistics. Retrieved from http://www.who.int/whosis/whostat/EN_WHS2011_Full.pdf

WHO. (2012). Millennium Development Goals (MDGs). Retrieved from http://www.who.int/topics/millennium_development_goals/en/.

Note

Note 1. National Environmental Management Authority (2005) A Preliminary report of the inter-ministerial committee investigating suspected hazardous waste dumping in North Eastern Province of Kenya. A case study of Garissa and Wajir districts. (obtained with permission). 